\title{
Hyperglycaemia potentiates the teratogenicity of retinoic acid in diabetic pregnancy in mice
}

\author{
M. B. W. Leung ${ }^{1}$ K.-W. Choy ${ }^{2}$ A. J. Copp ${ }^{3}$ C.-P. Pang ${ }^{2}$ A. S. W. Shum ${ }^{1}$ \\ ${ }^{1}$ Department of Anatomy, Faculty of Medicine, The Chinese University of Hong Kong, Hong Kong, People's Republic of China \\ 2 Department of Ophthalmology and Visual Sciences, Faculty of Medicine, The Chinese University of Hong Kong, Hong Kong, \\ People's Republic of China \\ ${ }^{3}$ Neural Development Unit, Institute of Child Health, University College London, London, UK
}

\section{Abstract}

Aims/hypothesis. We recently showed in mice that maternal diabetes increases embryonic susceptibility to caudal regression induced by vitamin A metabolite retinoic acid. Here we tested whether in the maternal diabetic milieu hyperglycaemia is the critical factor responsible for mediating this increased susceptibility. Methods. Non-diabetic pregnant mice were made hyperglycaemic by subcutaneous injections of glucose at regular intervals. Conversely, diabetic pregnant mice were treated with phlorizin to induce renal glucosuria and thus reduce blood glucose concentrations. Pregnant mice were treated with retinoic acid and the extent of caudal regression in mouse embryos, measured in terms of the ratio of tail length to crown-rump length was assessed. Embryos were also examined for Wnt-3a expression and cell death.

Results. Embryos of mice treated with glucose had a greater extent of caudal regression induced by retinoic acid than saline-treated controls, with enhanced downregulation of Wnt-3a expression and exacerbated cell death specifically at the caudal end of the embryo. Embryos of diabetic mice treated with phlorizin had a similar extent of caudal regression to embryos of nondiabetic mice after treatment with retinoic acid.

Conclusions/interpretation. Hyperglycaemia increases embryonic susceptibility to caudal regression induced by retinoic acid, with the underlying cellular and molecular changes closely mimicking those that occur in maternal diabetes. Reduction of blood glucose concentrations in diabetic mice completely abolishes this increased susceptibility to retinoic acid. These results suggest that in maternal diabetes hyperglycaemia is the critical factor responsible for potentiating the teratogenic effect of retinoic acid. [Diabetologia (2004) 47:515-522]

Keywords Caudal regression - Retinoic acid · Hyperglycaemia $\cdot$ Maternal diabetes $\cdot$ Wnt-3a . Cell death $\cdot$ Mouse embryo
Infants of mothers with diabetes mellitus are more prone to congenital malformation than those of nondiabetic pregnancies $[1,2]$. As most malformations in

Received: 24 September 2003 / Revised: 5 December 2003

Published online: 14 February 2004

(C) Springer-Verlag 2004

A. S. W. Shum (

Department of Anatomy, Faculty of Medicine,

The Chinese University of Hong Kong, Shatin, N.T.,

Hong Kong, People's Republic of China

E-mail: alisa-shum@cuhk.edu.hk

Abbreviations: RAR, retinoic acid receptors $\cdot \mathrm{RBP}$, retinol binding protein CRABP, cellular retinoic acid binding proteins infants of diabetic mothers are due to developmental errors at a very early stage of pregnancy [3], a better understanding of the risk factors that predispose these embryos to malformation could lead to better preconceptional care to prevent anomalies.

Although it is evident that diabetic embryopathy results from multifactorial interactions [4], few investigations of the association between diabetic embryopathy and other factors like food or drugs taken during pregnancy have been undertaken. Using the mouse as a model, we recently reported that embryos of diabetic mothers are more susceptible to the teratogenic effect of retinoic acid, the bioactive metabolite of vitamin A, in developing caudal regression [5]. The increased severity of caudal regression in embryos of diabetic 
mice after retinoic acid treatment was associated with enhanced down-regulation of Wnt-3a, a gene that is indispensable for the development of the caudal embryonic region, and exacerbated cell death specifically in the tail bud. However, it is not clear which factor or factors in the maternal diabetic milieu are responsible for the teratogenic interaction with retinoic acid.

In humans, effective glycaemic control during preconception and early gestation has generally led to a lower frequency of malformations $[6,7,8]$. Moreover, increased glucose concentrations in vivo and in vitro culture in excess glucose have been shown to be teratogenic in animal studies $[9,10,11]$. The purpose of our study, therefore, was to specifically test whether hyperglycaemia is the critical factor that increases embryonic susceptibility to caudal regression induced by retinoic acid.

\section{Materials and methods}

Animals. The colony of ICR mice at The Chinese University of Hong Kong was established from breeding pairs originally obtained from Harlan UK (Bicester, Oxon, UK) in 1998. The mice were kept under a 12:12 h light-dark cycle in a humidity-controlled room and fed with irradiated LabDiet for rodents (PMI Nutrition, Richmond, Ind., USA) and ozone-sterilised tap water.

The principles of laboratory animal care set forth by the NIH were followed and approval of all animal experimentation procedures was obtained from the Animal Experimentation Ethics Committee of The Chinese University of Hong Kong.

Induction of hyperglycaemia. Timed matings were set up between 8- to 10-week-old non-diabetic female and non-diabetic male ICR mice. Starting from day 8 of gestation, female mice received subcutaneous injections of $1 \mathrm{ml}$ of $25 \% \mathrm{D}$-glucose dissolved in PBS at 1.5-h intervals over a period of $16.5 \mathrm{~h}$. Control female mice received equivalent injections of PBS. Glucose concentrations in blood from the tail vein were measured using the Glucometer Elite (Bayer, Newbury, UK) every $1.5 \mathrm{~h}$. At the midpoint of glucose treatment, i.e. hour 8 on day 8 of gestation, pregnant mice received an intraperitoneal injection of $25 \mathrm{mg} / \mathrm{kg}$ body weight of all-trans retinoic acid (Sigma, St. Louis, Mo., USA) suspended in peanut oil, whereas control mice received an equivalent volume of suspension vehicle. The mice were killed at day 10.5 of gestation and embryos were removed from the uterus for analysis. To determine the extent of caudal regression, tail length (defined as the length of the caudal region from the posterior limit of the hindlimb bud to the end of the tail) and crown-rump length were measured using an eyepiece graticule on a stereomicroscope.

Phlorizin treatment. Diabetes was induced in 7- to 8-week-old female ICR mice by injecting streptozotocin to kill the insulinproducing pancreatic beta cells. This was done two weeks before mating as described previously [5]. Female mice were classified as diabetic if blood glucose concentrations were greater than $16.5 \mathrm{mmol} / \mathrm{l}$. Untreated age-matched female ICR mice served as non-diabetic controls (blood glucose concentration: $5.0-7.7 \mathrm{mmol} / \mathrm{l})$.

Diabetic or non-diabetic female mice were mated with nondiabetic male ICR mice. To induce renal glucosuria, starting from hour 12 on day 7 of gestation, pregnant mice received three intraperitoneal injections of $0.35 \mathrm{~g} / \mathrm{kg}$ body weight of phlorizin (Sigma), dissolved in $40 \%$ propylene glycol (Sigma), or an equivalent volume of suspension vehicle as control. Injections were given at 9 -h intervals. At hour 8 on day 8 of gestation mice were treated with $25 \mathrm{mg} / \mathrm{kg}$ retinoic acid. The tail length and crown-rump length of embryos were recorded at day 10.5 of gestation as described above.

Detection and semi-quantitation of Wnt-3a. To find out whether hyperglycaemia increased embryos' susceptibility to caudal regression induced by retinoic acid via similar molecular and cellular changes as observed in the interaction of retinoic acid with maternal diabetes, embryos were removed from the uterus $16 \mathrm{~h}$ after retinoic acid treatment, in order to examine the expression of Wnt-3a in the tail bud. Whole embryos were subjected to in situ hybridisation using digoxygeninlabelled probes [12, 13], whereas the tail buds of embryos from the same litter were pooled together and subjected to semi-quantitative RT-PCR analysis. Polymerase chain reaction was carried out using forward (5'-GAA TCT CTA TGG GGA CTG CTA GG) and reverse (5'-GTA TTA AGT GTC AGA GCG GAT GC) primers to amplify an 82 bp sequence corresponding to nucleotide sequences 2107-2127 and 2188-2166 of mouse Wnt-3a. Forward (5'-GAG ATT ACT GCT CTG GCT CC) and reverse (5'-GGA CTC ATC GTA CTC CTG C) primers were used to amplify a $150 \mathrm{bp}$ sequence corresponding to nucleotide sequences 868-887 and 1017-999 of mouse $\beta$-actin, which served as a positive control for mRNA preparation, and for semi-quantitative analysis of Wnt-3a mRNA expression. We did 30 PCR cycles, comprising: denaturation at $94^{\circ} \mathrm{C}$ for $30 \mathrm{~s}$, annealing at $55^{\circ} \mathrm{C}$ for $40 \mathrm{~s}$ and extension at $72^{\circ} \mathrm{C}$ for $30 \mathrm{~s}$. To ensure the cycle number was within the logarithmic phase, three tenfold serial diluted cDNA samples were used. The band volumes of Wnt-3a and $\beta$-actin were measured from digitised images using Quantity One quantitation software (Bio-Rad, Hercules, Calif., USA).

Whole-mount staining of dying cells. To compare the extent of cell death in the tail bud region of embryos under different treatments, the supravital dye Nile blue sulphate was used to stain dead cells in whole-mount preparations $24 \mathrm{~h}$ after treatment with retinoic acid or suspension vehicle, according to the protocol described previously [14].

Statistical analysis. Data on blood glucose concentrations were analysed by Student's $t$ test. Data on tail length, the ratio of tail length to crown-rump length and relative intensity of Wnt-3a to $\beta$-actin expression were analysed by one-way ANOVA, followed by the Bonferroni test and the Contrast test, using SPSS software (SPSS, Chicago, Ill., USA), with statistical significance set at a $p$ value of less than 0.05 .

\section{Results}

Hyperglycaemia in early stages of organogenesis increases embryonic susceptibility to retinoic acid. Injections of glucose at regular intervals $8 \mathrm{~h}$ before and $8 \mathrm{~h}$ after retinoic acid injection increased the blood glucose concentration from $6.8 \pm 0.2 \mathrm{mmol} / \mathrm{l}$ to a diabetic level of $17.9 \pm 3.2 \mathrm{mmol} / \mathrm{l}$ at the time of retinoic acid injection $(p<0.01)$. Without retinoic acid, the embryos of mice treated with glucose showed no morphological differences from the PBS-treated controls (Fig. 1a). In these two groups of embryos the tail length (data not shown) and the ratio of tail length to crown-rump 

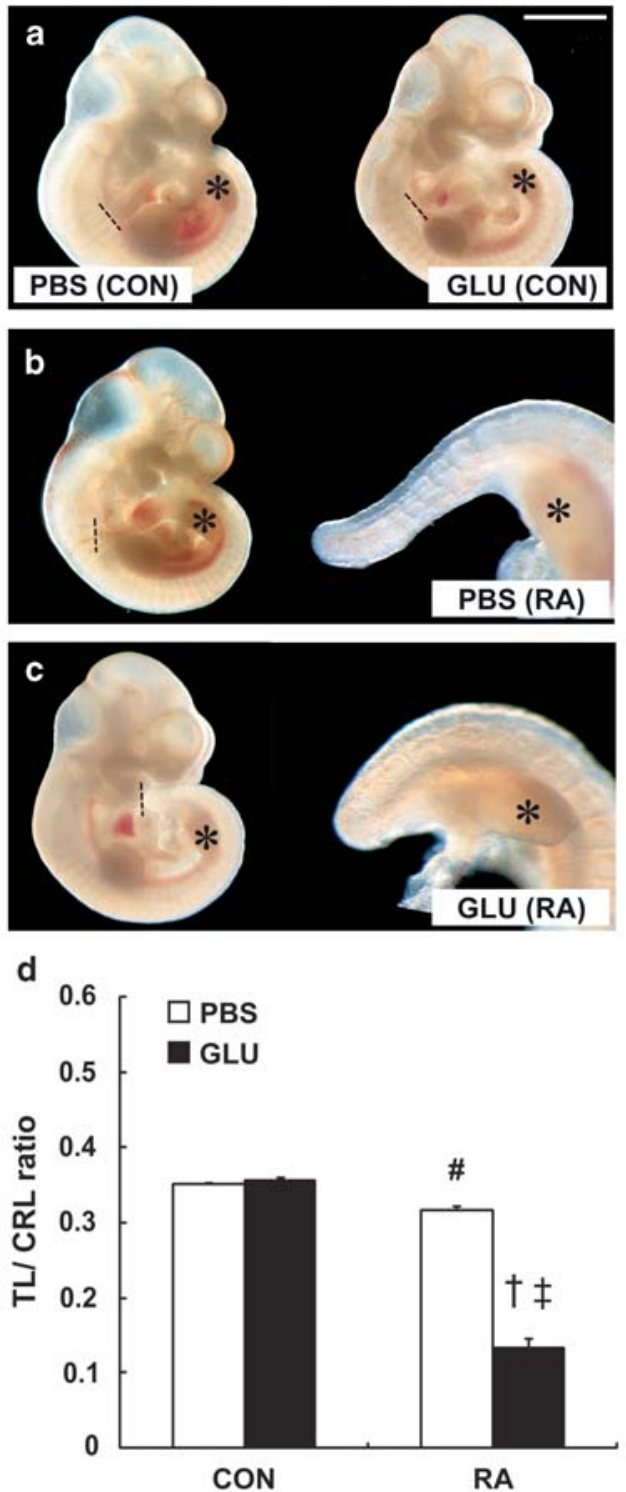

Fig. 1a-d. Effect of hyperglycaemia on susceptibility to caudal regression induced by retinoic acid. Morphological appearance $(\mathbf{a}-\mathbf{c})$ of embryos of PBS-treated mice (PBS) and glucose-treated mice (GLU) when exposed to $25 \mathrm{mg} / \mathrm{kg}$ retinoic acid (RA) or suspension vehicle as control $(\mathrm{CON}) .{ }^{*}$ marks the position of the hindlimb bud; the broken line marks the caudal limit of the tail. Note the striking caudal regression in embryos exposed to hyperglycaemia and RA (c). Scale bar: $1.5 \mathrm{~mm}$ and $0.5 \mathrm{~mm}$ in magnified caudal regions. Caudal regression reflected by reduction in the tail length to crown-rump length (TL/CRL) ratio (d) in embryos of different treatment groups. Values represent means \pm SEM. Analysis was by one-way ANOVA followed by Bonferroni test. Number of embryos: PBS(CON), $n=110$; GLU(CON), $n=136 ; \quad \mathrm{PBS}(\mathrm{RA}), \quad n=127 ; \quad \mathrm{GLU}(\mathrm{RA}), \quad n=108 . \quad{ }^{\#} p<0.05 \quad$ vs $\mathrm{PBS}(\mathrm{CON}) ;{ }^{\dagger} p<0.001$ vs GLU(CON); ${ }^{\ddagger} p<0.001$ vs PBS(RA)

length were very similar (Fig. 1d). Retinoic acid reduced tail length (data not shown) and the ratio of tail length to crown-rump length in both groups of embryos, but with a much greater reduction $(p<0.001$, analysed by one-way ANOVA followed by Contrast test) in embryos of mice treated with glucose
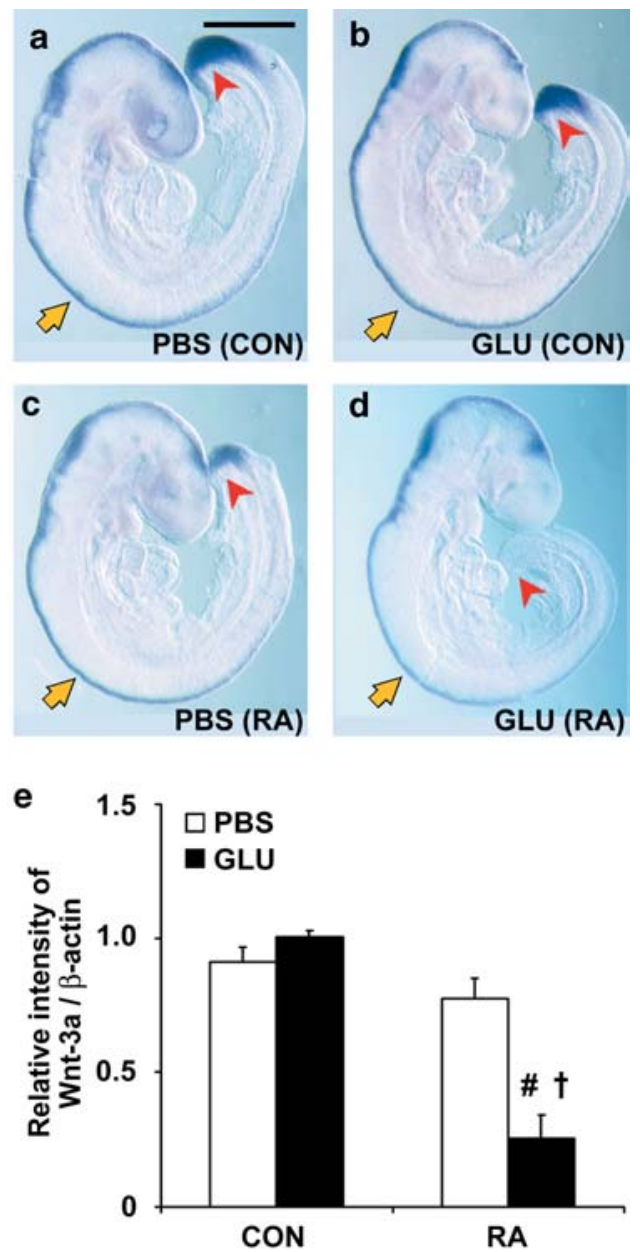

Fig. 2a-e. Effect of hyperglycaemia on expression level of Wnt-3a. In situ hybridisation (a-d) for Wnt-3a in embryos of PBS-treated mice (PBS) and glucose-treated mice (GLU) $16 \mathrm{~h}$ after treatment with $25 \mathrm{mg} / \mathrm{kg}$ retinoic acid (RA) or suspension vehicle as control (CON). The red arrowhead and yellow arrow mark the expression of Wnt-3a in the tail bud and neural tube respectively. Between 44 and 58 embryos were examined in each treatment group. The embryo of the PBS(RA) treatment group with the lowest observed expression level of tail bud Wnt-3a is shown in (c). Wnt-3a expression was extinguished in the tail bud of $20 \%$ of GLU(RA) embryos, as shown in a representative embryo $(\mathbf{d})$. Scale bar: $0.5 \mathrm{~mm}$. The graph (e) shows the relative intensity of Wnt-3a: $\beta$-actin PCR products. Values represent means \pm SEM. Analysis was by one-way ANOVA followed by Bonferroni test. Number of litters: PBS(CON), $n=8 ;$ GLU(CON), $n=3 ; \quad \operatorname{PBS}(\mathrm{RA}), n=9 ; \quad \mathrm{GLU}(\mathrm{RA}), n=6$. ${ }^{\#} p<0.001$ vs $\mathrm{GLU}(\mathrm{CON}) ;{ }^{\dagger} p<0.001$ vs $\mathrm{PBS}(\mathrm{RA})$

(Fig. 1c,d) than in the PBS-treated controls (Fig. 1b,d). Hence, embryos developing under hyperglycaemic conditions have increased susceptibility to caudal regression induced by retinoic acid.

Exposure to retinoic acid under hyperglycaemic conditions led to enhanced down-regulation of Wnt-3a and exacerbated cell death in the tail bud. Our examination of expression of Wnt-3a and the extent of cell death in the embryos found that exposure to hyperglycaemic 

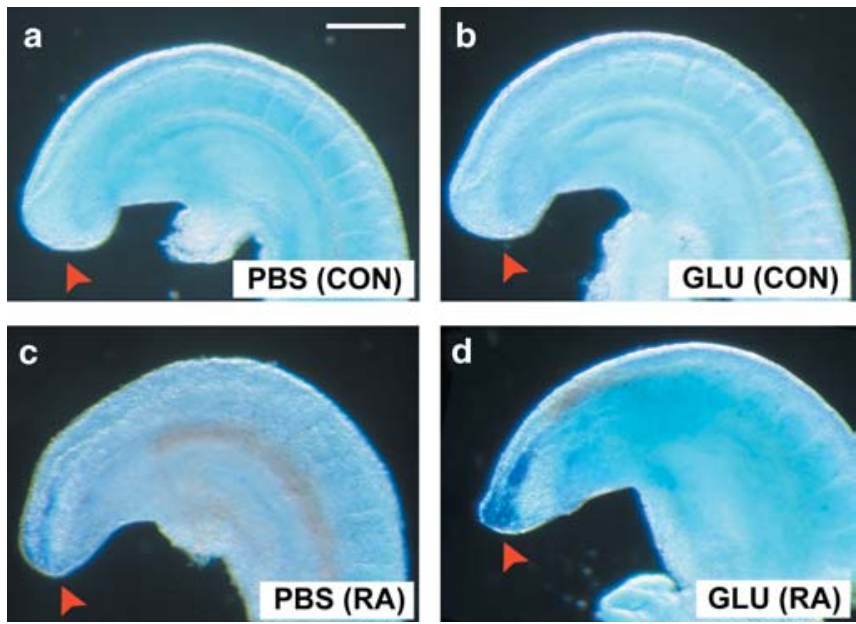

Fig. 3a-d. Effect of hyperglycaemia on cell death. Nile blue sulphate staining of dead cells in the caudal region of embryos of PBS-treated mice (PBS) and glucose-treated mice (GLU) $24 \mathrm{~h}$ after treatment with $25 \mathrm{mg} / \mathrm{kg}$ retinoic acid (RA) or suspension vehicle as control (CON). Dead cells appear dark blue, the arrowhead marks the position of the tail bud. Cell death was moderately increased in the PBS(RA) tail bud (c), but markedly increased in the GLU(RA) tail bud (d). Representative embryos from the 12 to 15 examined in each treatment group are shown. Scale bar: $0.2 \mathrm{~mm}$

conditions alone did not alter Wnt-3a expression in the tail bud of embryos in comparison with the PBS-treated controls (Fig. 2a,b,e). In contrast, after the injection of retinoic acid, Wnt-3a was down-regulated to a greater extent in the tail bud of embryos of mice treated with glucose (Fig. 2d,e) than in the tail bud of the PBS-treated controls (Fig. 2c,e; $p<0.001$, analysed by one-way ANOVA followed by Contrast test). In $20 \%$ of the embryos of mice treated with glucose $(n=58), W n t-3 a$ expression was completely extinguished in the tail bud $16 \mathrm{~h}$ after retinoic acid treatment (Fig. 2d), while the remaining $80 \%$ of these embryos had a very low level of Wnt-3a mRNA transcripts. However, in the group treated with PBS and retinoic acid ( $n=44)$, clearly detectable Wnt-3a mRNA transcripts occurred even in embryos with the lowest Wnt-3a expression level (Fig. 2c). The difference in Wnt-3a expression levels between the embryos of the PBS-treated and glucose-treated groups was restricted to the tail bud, with expression in the neural tube being unaffected by retinoic acid treatment (Fig. 2c,d), an observation that closely resembled the effect of maternal diabetes on Wnt-3a expression in embryos treated with retinoic acid.

Analysis of cell death by whole-mount supravital dye staining showed that cell death was not observed in the tail bud of embryos of mice treated with glucose or PBS alone (Fig. 3a,b). In contrast, $24 \mathrm{~h}$ after retinoic acid treatment, there were more dying cells in the tail bud of embryos in the group treated with glucose than in the PBS-treated controls (Fig. 3c,d). Maximum apoptosis was observed $24 \mathrm{~h}$ after retinoic acid treatment with lower levels before and after this time
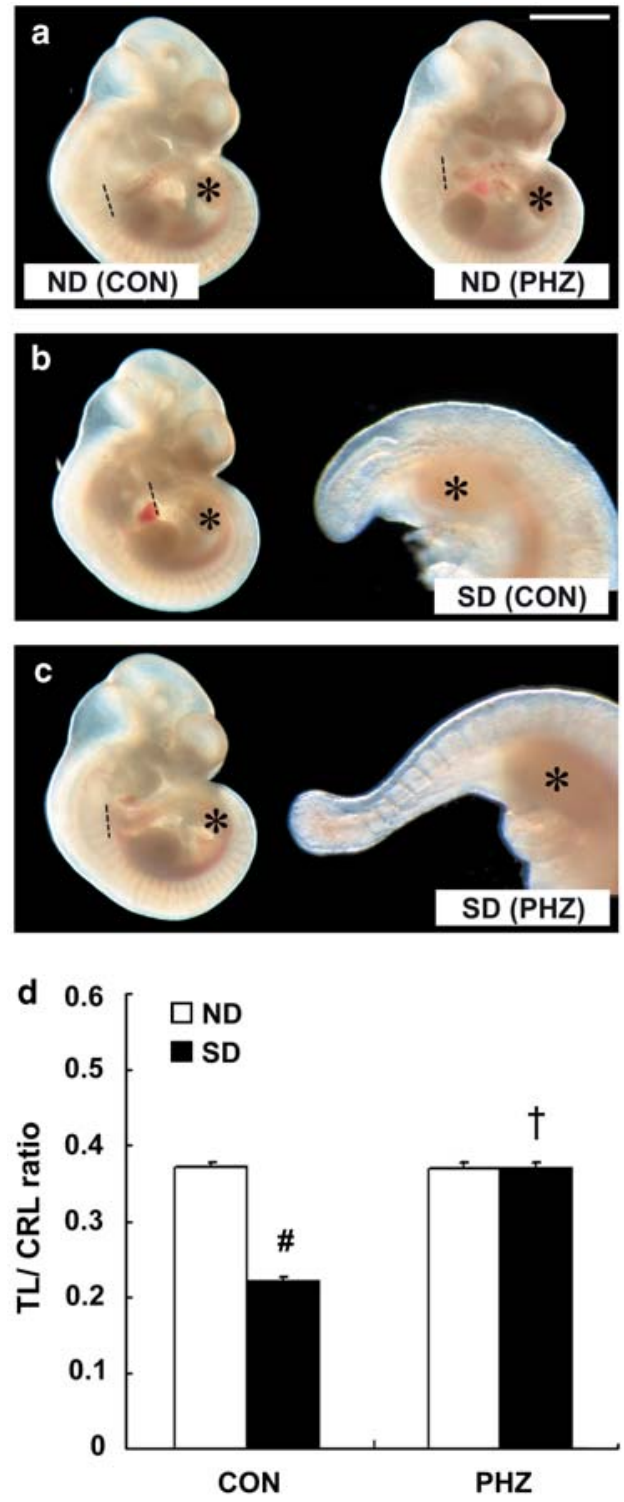

Fig. 4a-d. Effect of reducing blood glucose on susceptibility to caudal regression. Morphological appearance $(\mathbf{a}-\mathbf{c})$ of embryos of retinoic acid-treated non-diabetic mice (ND) and retinoic acid-treated diabetic mice (SD) that had been exposed to phlorizin $(\mathrm{PHZ})$ or suspension vehicle as control $(\mathrm{CON})$. * marks the position of the hindlimb bud; the broken line marks the caudal limit of the tail. Phlorizin treatment completely rescued caudal regression in embryos exposed to retinoic acid within a diabetic milieu (c). Scale bar: $1.5 \mathrm{~mm}$ and $0.5 \mathrm{~mm}$ in magnified caudal regions. Caudal regression reflected by reduction in the tail length to crown-rump length (TL/CRL) ratio (d) in retinoic acid-treated embryos of different treatment groups. Analysis was by one-way ANOVA followed by Bonferroni test. Values represent means \pm SEM. Number of embryos: $\mathrm{ND}(\mathrm{CON})$, $n=98 ; \mathrm{SD}(\mathrm{CON}), n=77$; $\mathrm{ND}(\mathrm{PHZ}), n=118 ; \mathrm{SD}(\mathrm{PHZ}), n=99$. ${ }^{\#} p<0.001$ vs $\mathrm{ND}(\mathrm{CON}) ;{ }^{\dagger} p<0.001$ vs $\mathrm{SD}(\mathrm{CON})$

point. Taken together, these findings indicate that the increased extent of caudal regression in embryos treated with retinoic acid under conditions of hyperglycaemia is associated with the same molecular and cellular changes as in maternal diabetes. 
Reduction of blood glucose concentrations completely abolishes the increased susceptibility to caudal regression induced by retinoic acid. After ascertaining that increased blood glucose interacts with retinoic acid in a similar way to maternal diabetes, we next tested whether the reduction of blood glucose concentrations could abolish the teratogenic interaction of maternal diabetes with retinoic acid. Administration of phlorizin to non-diabetic mice did not alter blood glucose concentrations or induce any morphological abnormalities (Fig. 4a), whereas our preliminary studies found that blood glucose concentrations of diabetic mice began to drop $12 \mathrm{~h}$ after phlorizin treatment. Hence, we started the phlorizin regime at hour 12 on day 7 of gestation, which led to a reduction $(p<0.001)$ in the blood glucose concentrations from $32.7 \pm 0.3 \mathrm{mmol} / \mathrm{l}$ before phlorizin treatment to $11.4 \pm 0.6 \mathrm{mmol} / \mathrm{l}$ at the time of retinoic acid injection (hour 8 , day 8 ). With this reduction in blood glucose concentrations, the caudal region of embryos of retinoic acid-treated diabetic mice injected with phlorizin (Fig. 4c) became morphologically indistinguishable from embryos of retinoic acid-treated non-diabetic mice (Fig. 4a). This was in marked contrast to the embryos of retinoic acid-treated diabetic control mice injected with vehicle, which had severe caudal regression (Fig. 4b). The tail length (data not shown) and the ratio of tail length to crown-rump length (Fig. 4d) of embryos of retinoic acid-treated diabetic mice injected with phlorizin were so much increased that there was no difference between the diabetic and non-diabetic mice treated with retinoic acid (Fig. 4d). Taken together, these results indicate that the increased susceptibility to caudal regression induced by retinoic acid in diabetic pregnancy can be completely abolished by lowering blood glucose concentrations to near normal levels.

\section{Discussion}

In this study, we show that induction of hyperglycaemia during the early stages of organogenesis in non-diabetic mice can mimic maternal diabetes by increasing embryonic susceptibility to caudal regression induced by retinoic acid. Apart from increasing blood glucose concentrations, the repeated subcutaneous injection of D-glucose probably also affects other metabolic pathways and leads to an increase in insulin concentrations. Nevertheless, the increased susceptibility to retinoic acid in embryos of streptozotocin-induced insulin-deficient diabetic mice was completely abolished by selective reduction of blood glucose concentrations via specific inhibition of renal tubular reabsorption of glucose using phlorizin [15]. Thus, irrespective of possible changes in other metabolic pathways, our findings strongly suggest that hyperglycaemia in the maternal diabetic milieu is the critical factor that interacts with retinoic acid.
Several studies have reported multiple abnormalities in embryos developing under conditions of hyperglycaemia induced either by in vitro culture in serum supplemented with glucose, or by in vivo injection of glucose $[9,10,11]$. In contrast, we found that embryos of mice treated with glucose closely resembled embryos of PBS-treated control mice. The lack of apparent morphological abnormalities in embryos treated with glucose suggests that in the present study hyperglycaemia in itself was probably not teratogenic. In fact, although hyperglycaemia down-regulates developmentally important genes and induces cell death in tissues such as the neural tube [10], we found no change in the expression level of Wnt-3a, nor any increase in cell death in the tail bud under hyperglycaemic conditions alone. Yet, when exposed to retinoic acid, embryos developing under conditions of maternal hyperglycaemia had enhanced down-regulation of Wnt-3a and exacerbated cell death in the tail bud, compared with embryos developing under normoglycaemic conditions. This suggests that the interaction between hyperglycaemia and retinoic acid is not additive, but rather hyperglycaemia potentiates the teratogenicity of retinoic acid.

What are the mechanisms by which the teratogenicity of retinoic acid is increased in mice under hyperglycaemic conditions? The extent of caudal regression induced by retinoic acid, in non-diabetic mice, is dependent on developmental stage [14]. Some studies have shown that streptozotocin-induced diabetic rat embryos are retarded in growth and development [16]. Others, however, report that mouse embryos of streptozotocin-induced diabetic mothers or embryos cultured in serum supplemented with high glucose are not developmentally delayed or growth-retarded [5, $11,17]$. We examined embryos $24 \mathrm{~h}$ after the beginning of glucose injections and found no differences in morphology or somite number compared with PBStreated control embryos, regardless of whether or not the mice had received retinoic acid (glucose-treated controls: $16.9 \pm 0.3$ somites; PBS-treated controls: 17.1 \pm 0.6 ; glucose and retinoic acid-treated: $17.3 \pm 0.3$; PBS and retinoic acid-treated: 17.1 \pm 0.5 ; unpublished data by one of the authors). Hence, developmental delay is unlikely to account for the increased susceptibility of embryos from hyperglycaemic pregnancy to caudal regression induced by retinoic acid.

The teratogenic effect of retinoic acid is highly dose-dependent $[14,18]$, raising the possibility that the amount of retinoic acid delivered to the embryo or taken up by the cell could be enhanced under maternal hyperglycaemia, thereby increasing the incidence of malformations induced by retinoic acid. Blood flow to the uterine and decidual tissues is increased during the early stages of pregnancy in diabetic rats [19], suggesting that retinoic acid could be delivered to developing embryos at an increased concentration under conditions of hyperglycaemia. Retinoic acid in the 
embryo is synthesised from vitamin A (retinol) obtained from the maternal circulation. Hence, a further level of regulation of retinoic acid bioavailability can be provided by the retinol binding protein (RBP), the cellular retinol binding proteins I and II, and the cellular retinoic acid binding proteins (CRABP) I and II, which are expressed in the yolk sac, placental tissues and also in highly regulated patterns in the embryo $[20,21,22,23]$. In fact, levels of RBP are reduced in the plasma, liver and kidney of streptozotocin-induced diabetic rats, diabetic Biobreeding (BB) rats and Type 1 diabetic patients [24, 25, 26, 27]. It is not known whether levels of the various retinoid binding proteins are altered in placental and embryonic tissues under hyperglycaemic conditions, which could affect the availability of retinoic acid to specific embryonic tissues, thereby enhancing the teratogenic effect of retinoic acid. For instance, CRABP sequesters free retinoic acid, thus preventing it from binding to the retinoic acid receptors (RAR) in regions of the embryo, such as the tail bud, where normal development requires low retinoic acid concentrations [22, 23, 28]. Hence, if CRABP levels are reduced in the embryo under conditions of hyperglycaemia, this could enhance the teratogenic effect of retinoic acid on the tail bud.

Alteration of the catabolism of retinoic acid provides a further level of regulation of retinoic acid teratogenicity. Retinoic acid plays an essential role in many developmental processes [29]. Both an excess and a deficiency of retinoic acid result in an overlapping array of malformations that affect the same target organ systems in the offspring [30, 31, 32], showing that the concentration of retinoic acid needs to be tightly regulated for normal development. The major retinoic acid catabolising enzyme is $C Y P 26$, which is expressed specifically in the caudal embryonic region, from the tail bud to the presomitic region [33], and catabolises retinoic acid that is synthesised and diffuses from the anterior somitic tissue [34]. Targeted disruption of $C Y P 26$ in mice leads to caudal regression syndrome [28], with the extent of axial truncation closely resembling that induced by exogenous retinoic acid [14]. In mice and rats, CYP26 mRNA expression is positively regulated by vitamin A [35]. Moreover, vitamin A levels are lowered in humans with Type 1 diabetes $[27,36,37,38]$ and in rodents with streptozotocin-induced diabetes [39]. It is possible, therefore, that a reduction of vitamin $\mathrm{A}$ in the plasma of diabetic mothers leads to reduced CYP26 expression in the embryo, diminishing the embryo's ability to catabolise exogenous retinoic acid, and thereby enhancing retinoic acid teratogenicity.

Apart from affecting uptake, availability or catabolism of retinoic acid, maternal hyperglycaemia could also intervene in retinoic acid signalling by altering the efficacy of signal transduction. The action of retinoic acid is mediated via the formation of complexes with nuclear RAR, which then bind to cis-acting retinoic acid response elements of target genes to activate, or sometimes inhibit their transcription. The several known RAR isoforms are expressed in spatially and temporally restricted embryonic domains [22, 23]. For instance, $R A R-\gamma$ is expressed in the tail bud, but not in the neural tube [23]. Embryos homozygous for a loss-of-function mutation in $R A R-\gamma$ are resistant to caudal regression induced by retinoic acid, showing that $R A R-\gamma$ is involved in mediating the effect of retinoic acid in the tail bud [40]. Hence, it is possible that retinoic acid-induced down-regulation of Wnt-3a is mediated via $R A R-\gamma$, leading to specific reduction of $W n t-3 a$ in the tail bud, but not in the neural tube. It has been shown that the expression levels of different RAR isoforms are reduced to various extents in embryonic tissues of animals deficient in vitamin A [41]. In adult tissues, interestingly, RAR isoforms whose expression is reduced to the greatest extent under conditions of vitamin A deficiency are induced several times more plentifully by exogenous retinoic acid than RAR isoforms that are not affected by vitamin A deficiency [42]. As reduced vitamin A availability is associated with diabetes $[27,36,37,38,39]$, it is possible that the expression of RAR isoforms regulated by retinoic acid, e.g. $R A R-\gamma$, is reduced in embryos under maternal hyperglycaemia. If exogenous retinoic acid up-regulates embryonic $R A R-\gamma$ to a greater extent in hyperglycaemic than in normoglycaemic conditions, this could result in enhanced down-regulation of Wnt-3a, specifically in the tail bud, as observed in this study.

In conclusion, our study shows that hyperglycaemia increases the susceptibility of mouse embryos to the teratogen, retinoic acid. This underlines the importance of tight glycaemic control during early diabetic pregnancy when the risk of congenital malformation is highest. It is known that vitamin A supplementation increases levels of retinoic acid in human plasma [43] and animal studies further show that vitamin A teratogenesis results from increased embryonic concentrations of retinoic acid [44]. Together with growing evidence that vitamin A levels are altered in diabetic patients [27, 36, 37, 38], which could thus affect the availability, catabolism or signal transduction of retinoic acid in the embryo as discussed earlier, our findings of an interaction between hyperglycaemia and retinoic acid suggest that, in addition to tight glycaemic control, close monitoring of maternal plasma vitamin A levels during preconception and early gestation may reduce the risk of congenital malformation in diabetic pregnancy.

Acknowledgements. This work was substantially supported by a grant from the Research Grants Council of the Hong Kong Special Administrative Region (CUHK4298/97M, to A.S.W. Shum and A.J. Copp). The seed funding was provided by a Direct Grant for Research from The Chinese University of Hong Kong (CUHK) (2040806 and 2040878, to A.S.W. 
Shum). M.B.W. Leung was supported by a CUHK Postgraduate Studentship. A.J. Copp was supported by the Wellcome Trust, UK. We thank M. Loeken for technical advice on induction of hyperglycaemia and phlorizin treatment, Y.K. Tse (Centre for Clinical Trials and Epidemiological Research, CUHK) for advice on statistical data analysis, and R. Nusse for the gift of mouse Wnt-3a cDNA plasmids.

\section{References}

1. Chung CS, Myrianthopoulos NC (1975) Factors affecting the risks of congenital malformations. II. Effect of maternal diabetes on congenital malformations. Birth Defects Orig Artic Ser 11:23-38

2. Hawthorne G, Robson S, Ryall EA, Sen D, Roberts SH, Ward Platt MP (1997) Prospective population based survey of outcome of pregnancy in diabetic women: results of the Northern Diabetic Pregnancy Audit, 1994. BMJ 315:279_ 281

3. Mills JL, Baker L, Goldman AS (1979) Malformations in infants of diabetic mothers occur before the seventh gestational week: Implications for treatment. Diabetes 28:292293

4. Reece EA, Homko CJ, Wu YK (1996) Multifactorial basis of the syndrome of diabetic embryopathy. Teratology 54: $171-182$

5. Chan BW, Chan KS, Koide T et al. (2002) Maternal diabetes increases the risk of caudal regression caused by retinoic acid. Diabetes 51:2811-2816

6. Kitzmiller JL, Gavin LA, Gin GD, Jovanovic-Peterson L, Main EK, Zigrang WD (1991) Preconception care of diabetes. Glycemic control prevents congenital anomalies. JAMA 265:731-736

7. Langer O, Conway DL (2000) Level of glycemia and perinatal outcome in pregestational diabetes. J Matern Fetal Med 9:35-41

8. Suhonen L, Hiilesmaa V, Teramo K (2000) Glycaemic control during early pregnancy and fetal malformations in women with type I diabetes mellitus. Diabetologia 43:79-82

9. Gale TF (1991) Effects of in vivo exposure of pregnant hamsters to glucose. 1. Abnormalities in LVG strain fetuses following intermittent multiple treatments with two isomers. Teratology 44:193-202

10. Fine EL, Horal M, Chang TI, Fortin G, Loeken MR (1999) Evidence that elevated glucose causes altered gene expression, apoptosis, and neural tube defects in a mouse model of diabetic pregnancy. Diabetes 48:2454-2462

11. Sadler TW (1980) Effects of maternal diabetes on early embryogenesis: II. Hyperglycemia-induced exencephaly. Teratology 21:349-356

12. Wilkinson DG (1992) Whole mount in situ hybridisation of vertebrate embryos. In: Wilkinson DG (ed) In situ hybridisation. IRL Press, Oxford, pp 75-83

13. Roelink H, Nusse R (1991) Expression of two members of the Wnt family during mouse development-restricted temporal and spatial patterns in the developing neural tube. Genes Dev 5:381-388

14. Shum ASW, Poon LLM, Tang WWT et al. (1999) Retinoic acid induces down-regulation of $W n t-3 a$, apoptosis and diversion of tail bud cells to a neural fate in the mouse embryo. Mech Dev 84:17-30

15. Rossetti L, Smith D, Shulman GI, Papachristou D, DeFronzo RA (1986) Correction of hyperglycemia with phlorizin normalizes tissue sensitivity to insulin in diabetic rats. J Clin Invest 79:1510-1515
16. Eriksson UJ, Lewis NJ, Freinkel N (1984) Growth retardation during early organogenesis in embryos of experimentally diabetic rats. Diabetes 33:281-284

17. Phelan SA, Ito M, Loeken MR (1997) Neural tube defects in embryos of diabetic mice. Role of the Pax-3 gene and apoptosis. Diabetes 46:1189-1197

18. Shenefelt RE (1972) Morphogenesis of malformations in hamsters caused by retinoic acid: relations to dose and stage at treatment. Teratology 5:103-118

19. Wentzel P, Jansson L, Eriksson UJ (1995) Diabetes in pregnancy: uterine blood flow and embryonic development in the rat. Pediatr Res 28:598-606

20. Bavik C, Ward SJ, Chambon P (1996) Developmental abnormalities in cultured mouse embryos deprived of retinoic acid by inhibition of yolk-sac retinol binding protein synthesis. Proc Natl Acad Sci USA 93:3110-3114

21. Sapin V, Ward SJ, Bronner S, Chambon P, Dolle P (1997) Differential expression of transcripts encoding retinoid binding proteins and retinoic acid receptors during placentation of the mouse. Dev Dyn 208:199-210

22. Dollé P, Ruberte E, Leroy P, Morriss-Kay G, Chambon P (1990) Retinoic acid receptors and cellular retinoid binding proteins. I. A systematic study of their differential pattern of transcription during mouse organogenesis. Development 110:1133-1151

23. Ruberte E, Dolle P, Chambon P, Morriss-Kay G (1991) Retinoic acid receptors and cellular retinoid binding proteins. II. Their differential pattern of transcription during early morphogenesis in mouse embryos. Development 111: 45-60

24. Tuitoek PJ, Ritter SJ, Smith JE, Basu TK (1996) Streptozotocin-induced diabetes lowers retinol-binding protein and transthyretin concentrations in rats. Br J Nutr 76:891897

25. Krill D, O'Leary L, Koehler AN et al. (1997) Association of retinol binding protein in multiple-case families with insulin-dependent diabetes. Hum Biol 69:89-96

26. Lu J, Dixon WT, Tsin AT, Basu TK (2000) The metabolic availability of vitamin A is decreased at the onset of diabetes in BB rats. J Nutr 130:1958-1962

27. Baena RM, Campoy C, Bayes R, Blanca E, Fernandez JM, Molina-Font JA (2002) Vitamin A, retinol binding protein and lipids in type 1 diabetes mellitus. Eur J Clin Nutr 56: 44-50

28. Abu-Abed S, Dolle P, Metzger D, Beckett B, Chambon P, Petkovich M (2001) The retinoic acid-metabolizing enzyme, CYP26A1, is essential for normal hindbrain patterning, vertebral identity, and development of posterior structure. Genes Dev 15:226-240

29. Maden M (2000) The role of retinoic acid in embryonic and post-embryonic development. Proc Nutr Soc 59:65-73

30. Ozeki H, Shirai S (1998) Developmental eye abnormalities in mouse fetuses induced by retinoic acid. Jpn J Ophthalmol 42:162-167

31. Yasuda Y, Konishi H, Kihara T, Tanimura T (1987) Developmental anomalies induced by all-trans-retinoic acid in fetal mice: II. Induction of abnormal neuroepithelium. Teratology 35:355-366

32. Dickman ED, Thaller C, Smith SM (1997) Temporallyregulated retinoic acid depletion produces specific neural crest, ocular and nervous system defects. Development 124:3111-3121

33. Fujii H, Sato T, Kaneko S et al. (1997) Metabolic inactivation of retinoic acid by novel P450 differentially expressed in developing mouse embryos. EMBO J 16:4163-4173

34. Swindell EC, Thaller C, Sockanathan S, Petkovich M, Jessell TM, Eichele G (1999) Complementary domains of 
retinoic acid production and degradation in the early chick embryo. Dev Biol 216:282-296

35. Yamamoto Y, Zolfaghari R, Ross AC (2000) Regulation of CYP26 (cytochrome P450RAI) mRNA expression and retinoic acid metabolism by retinoids and dietary vitamin $\mathrm{A}$ in liver of mice and rats. FASEB J 14:2119-2127

36. Basu TK, Basualdo C (1997) Vitamin A homeostasis and diabetes mellitus. Nutrition 13:804-806

37. Olmedilla B, Granado F, Gil-Martinez E, Blanco I, RojasHidalgo E (1997) Reference values for retinol, tocopherol, and main carotenoids in serum of control and insulindependent diabetic Spanish subjects. Clin Chem 43:10661071

38. Granado F, Olmedilla B, Gil-Martinez E, Blanco I, Millan I, Rojas-Hidalgo E (1998) Carotenoids, retinol and tocopherols in patients with insulin-dependent diabetes mellitus and their immediate relatives. Clin Sci (Lond) 94:189-195

39. Tuitoek PJ, Ziari S, Tsin AT, Rajotte RV, Suh M, Basu TK (1996) Streptozotocin-induced diabetes in rats is associated with impaired metabolic availability of vitamin A (retinol). Br J Nutr 75:615-622
40. Lohnes D, Kastner P, Dierich A, Mark M, LeMeur M, Chambon P (1993) Function of retinoic acid receptor gamma in the mouse. Cell 73:643-658

41. Cui J, Michaille JJ. Jiang W, Zile MH (2003) Retinoid receptors and vitamin A deficiency: differential patterns of transcription during early avian development and the rapid induction of RARs by retinoic acid. Dev Biol 260:496511

42. Haq RU, Pfahl M, Chytil F (1991) Retinoic acid affects the expression of nuclear retinoic acid receptors in tissues of retinol-deficient rats. Proc Natl Acad Sci USA 88:82728276

43. Eckhoff $\mathrm{CH}$, Nau H (1990) Vitamin A supplementation increases levels of retinoic acid compounds in human plasma: possible implications for teratogenesis. Arch Toxicol 64:502-503

44. Tzimas G, Collins MD, Burgin H, Hummler H, Nau H (1996) Embryotoxic doses of vitamin A to rabbits result in low plasma but high embryonic concentrations of all-transretinoic acid: risk of vitamin A exposure in humans. J Nutr 126:2159-2171 